\title{
Interview with Stephen Penneck
}

\author{
Kirsten West \\ Interview Editor, Statistical Journal of the IAOS \\ E-mail: kwestiaos@gmail.com
}

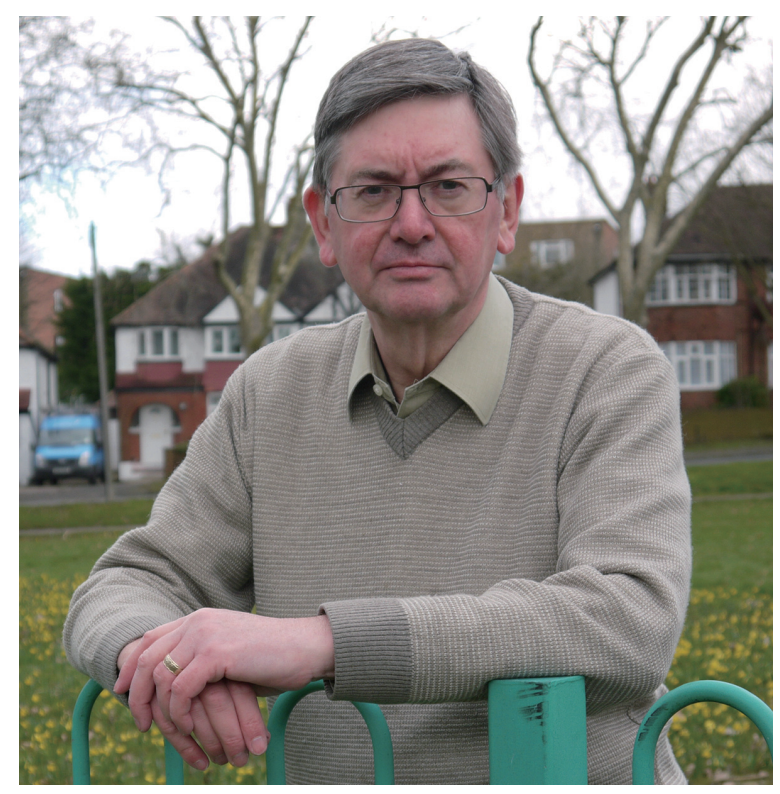

Before we talk about your contributions to official statistics, the ISI, the IAOS, and the SJIAOS, let us focus on you. Our readers hail from many different parts of the world and it is always interesting to note what sets us apart and what brings us together besides our shared interest in statistics.

Please give us some personal history. Where did you grow up, what special childhood experiences or childhood influences brought you to the field of statistics? Where did you receive your education?

I grew up not very far from where I am today, in Sutton, which is a suburb on the south side of London. It is within the London commuting area. It is easy to get into town, but it also on the edge of the Surrey Downs and near to the countryside. It is actually a very nice part of the country to live in, and I have been here in this area nearly all my life apart from the years when I attended university (BSc in Economics and Statistics at Southampton University and a MSocSc in Econo- metrics from Birmingham University.) I came back to more or less the same area.

So I spent my childhood here and I went to school here.

In terms of statistical influences in my childhood, I was always good at math. It was something that I took to at an early age. I had some exceptional math teachers, particularly in high school, who really knew how to teach the subject. I thought it was something that I could do. That was good.

I got involved in politics early on, when I was still in school and developing an interest in the wider world. Social science was something that I moved towards in the sixth form, ${ }^{1}$ where I studied Economics.

When it became time to choose subjects to study at university I picked Economics and Statistics. Those subjects brought things together for me. I think it was an interest in the economies of the world and the wider social issues and the politics of the time, that motivated me.

But I was also interested in how you measure things, how you know what is happening. This is where my background and interest in mathematics and statistics came in. I wanted to know how you know what you know. The disciplines I studied brought it all together.

Interviewer: Many statisticians we have interviewed for the Journal have attended graduate school in the United States. It almost seems to be the norm to come to the States to receive advanced training in statistics. However, you did not take that path. You received all your formal education in England.

That is correct. I actually did have the offer to come to the States to study for my PhD after I had done my

\footnotetext{
${ }^{1}$ In the English educational system, from the age of 16 , there is a two-year period of education known as "sixth form" or "college" which typically leads to A-level qualifications (similar to a high school diploma in some other countries), or a number of alternate qualifications such as BTEC, the International Baccalaureate or the Cambridge Pre-U.
} 
Master's Degree in Birmingham. I studied under a US professor, who was visiting at Birmingham for a year. When he went back to the States, he was very eager for me to go with him. There were two of us [students] who were studying econometrics and he was very keen for us to come and work with him in his $\mathrm{PhD}$ program. In the end, I decided not to go for a number of reasons, not the least financial. I needed to work. I needed to earn some money.

I was also partially committed getting a job in government statistics. They had a scheme called Cadet Statisticians. They have stopped it now because they cannot afford it anymore. But at the time, they sponsored students to do Master's degrees. In essence, you got a small salary to get your Master's degree under the condition that you would work for them afterwards. I felt I would be letting them down if I went [to the States]. So I did not do that PhD. Sometimes, I have regretted it a little because people seem to assume that everybody is a doctor these days. On the other hand, I do not regret that I got off to an early start on my career in the civil service.

Interviewer: And indeed, you have had a very distinguished civil service career, culminating with the position as Director General, heading a national statistical office with a staff of several thousands. You have a proven record in your leadership in official statistics.

Interviewer: Even though it seems that United States has such a draw on students from abroad, we should not forget that this is also the case for the United Kingdom. In your opinion, what are the strongholds of the UK system?

I did get some advice before I made my decision. I talked to a few friends who were more in the academic field, and they said that if you want a PhD in Statistics you will do far better in the UK than in the States. So comparisons were being made, and differences were drawn between the two systems.

The UK has a good educational system. It is attractive to people and it has a good reputation. We have high standards. There is a good balance between teaching and research. You have good people in the universities teaching the basics and that is good for young students. When I was working in the ONS, we employed quite a few people with $\mathrm{PhD}$ degrees and they had benefitted enormously from the work that they had done to get the degree.

As to why the US and the UK have such a draw on students seeking advanced degrees, I think both of our countries (the US and the UK) benefit from having English as our mother tongue. It is an advantage. A lot of
PhD students who come to the UK from other countries do so particularly because they want to learn English. I think that is a big attractor as well.

Interviewer: Is it the case in England that the advanced training in statistics is preparing the students to go into the academic field more so than pursuing a career as a civil servant?

I think that is the case. I told you that after I had done my first degree, I took the job as Cadet Statistician. I applied for the job as a civil servant after my first degree and was interviewed and talked to the people there. However, I did not feel that my first degree had taken me far enough in terms of what I thought I needed to do as a civil servant, as an official statistician. We discussed that and they said, "Why don't you do a Master's degree? Why don't you do a little bit more? You might find that helpful." So that is what I did and I did find it to be helpful.

I believe that to learn about 'surveys', for example, you need more than one class. Taking several classes, doing it again, gives you a chance to reflect a little bit more. I think in the first course you are being introduce to the material. In the second course, you have the chance to put it all together. You have done all the theories, sampling theory, probability and so on but you don't really get more than an overview unless you take more advanced classes.

I think the one year Master's degree pulls things together and adopts more of a principled approach to statistics. It is really helpful, and when you are faced with problems later on and you are trying to think of solutions to issues, statistical issues, you are successful when you have a good theoretical foundation to build on.

Interviewer: Before we continue talking about your career, let us stay with your personal life, because I know that you and your wife, who is also a statistician, raised a family along the way, and I am curious to learn how you went about doing that in England in the 1980s. What support was available to you. Were family-friendly policies in place? How did the workplace embrace young families? Has anything changed? How does one manage work and family life in England?

It was and is difficult. Pauline, my wife, is a statistician as well and she was also in the civil service. That happens of course quite often as people meet in college or in the workplace. We both wanted to work as civil servants. I think the public sector in this country is far more advanced than so many other countries, in child care support, or perhaps in understanding the issue, much more so than the private sector. 
My wife was able to take maternity leave, but when it was time for her to return to work we negotiated with our employers that we would both work part-time and share child care between us

We did it for quite a few years - five actually. I was at home for a couple of days every week, teaching the kids how to swim, taking them to after school activities and so on.

Being able to take a regular part in the children's upbringing was a privilege many fathers did not have in those days. It was possible to do it, but there was some downside in turns of one's career.

When I told my boss and people at work that I wanted to work part time because we wanted to raise a family and that is the way my wife and I had agreed to do it, my boss was very keen about it and positive and said, 'Why not!' But then he tried to find a position for me. It was much more difficult than we had thought.

Remember that this was in the 1980s and things have changed. But back then, when I explained my position to the managers of the statistics divisions, they were really quite dismissive, saying they only had full time jobs. It was some kind of 'ego-thing' to have full time employees. They would not accept that the job could be done in three or four days a week.

In the end, the job that I got, was a job that was below my grade level. It was an assistant's job. That experience was a bit morale shattering.

Even after I returned to full-time work I was questioned whether I was serious about my career, because my choice of part-time work had made me seem less committed to my work. It did slow down my career for a few years, compared with some of my contemporaries.

Of course, later on, down-the-road, I was able to benefit from that experience. And it gave me experience of juggling priorities. I had a good sense of the difficulties that young people face, just starting up their families. It is sometimes difficult to do both well.

Looking back, I am grateful to the few people who allowed us to do it our way. Perhaps they had some foresight. Because that is what it amounts to. As an employer that is what you have to think about. Is this person worth it? What are the long-term prospects? Is it in my interest to try to work out a flexible system for this person to be able to carry out his work? Will we get some advantage from this in the long term? If you think the answer is affirmative, then as an employer you really do want to make the arrangements work.

And before we move on to your next question and close this topic, I should add, than my wife and I were also lucky that we were able to live on one salary. That is not always the case and less so today, perhaps. It is more difficult to make ends meet today with just one income. Even if they want to, not all people can afford to work part time or take a big drop in their salary.

I should also add, that even with all my good will towards such arrangements, when I became a boss, I could not always do what I wanted to do for my employees. Of course, I was open to talk about it, and I understood their position.

In particular, when I think about women at work, and this is not a sexist observation, you often see the spark, the potential, when they are trying hard to do everything right and overcome all the hurdles of working outside the home and also raising a family. As a leader you have to encourage them to give as much as they can on the work side, and make them understand that they will be valued in the end. They need to see the importance of keeping one foot in the door.

Interviewer: You retired in 2012 as Director General at the UK Office for National Statistics (ONS). Tell us about your years at ONS. What are some of the best moments? What were some of the hardest challenges and how did you try to overcome them?

OK. I worked within the changing organizational structure of ONS. It was the Central Statistical Office (CSO) when I started out as a young Cadet Statistician in 1972. It was a small department, mostly involved with coordination of the statistical system. It gradually expanded and took on a lot of functions, especially in economic and financial statistics. I started out as an Assistant Statistician in the Department of Trade and Industry (DTI). In that department I worked on company financial statistics, insurance and pension fund statistics, monthly engineering sales, and the index of production and so on. DTI did all the business surveys. They also had some inputs into the National Accounts. All of these functions are now within the ONS, but at the time they were in the DTI.

So I worked in economic statistics, methodology and statistical policy. My wife, Pauline, is also an economic statistician, but we worked in different areas. As our careers developed she rather deliberately did not work in the same areas as me. She finally worked in the Tax Department. We tried to make sure that we did not cross paths too often in our working lives.

Though there was one time when we did work together. When I was the Director of the Statistical Out- 
puts Group in the ONS, I was asked by Len Cook, ${ }^{2}$ the National Statistician at the time, to look into our Pension Statistics which were not working so well and we were talking about who I should have on the team. He said that he had someone in mind, someone who was an expert in Pension Statistics. "Who do you think it is?" "Pauline!!" And then he said, "I am going to ask Pauline Penneck to be on your team."

We worked together for about four months. Afterwards we said that we were right when we said that we should not work together. In general, it is probably a good idea to keep a bit of separation when a married couple work in the same setting. You do not want to be discussing office problems when you are at home.

At ONS, my work developed into the areas of Economic Statistics and National Accounts and then more generally into surveys. From 1997 to 2000, I was the Director for National Accounts and from 2000 to 2003, I was the Divisional Director for National Statistics and Policy. I was the Director of Surveys and Administrative Sources from 2005 to 2008 when I became Director of Methodology. Then, finally, in 2009 and until I retired in 2012, I served as the Director General.

These were very happy times for me being involved with methodology and economic statistics, adding value to what everybody was trying to do.

You asked about the best moments. One for me came in 2002 when Len arranged for me to spend six months on secondment to the Australian Bureau of Statistics. Dennis Trewin, the Australian Statistician, integrated me into the management structure and I had a first class view of how that organisation functioned. I learned a lot: that all statistics offices face the same issues - what we can gain from better collaboration; the differences in culture in the two offices and how important culture is to corporate performance. It also gave me a much better sense of what ONS did well, as well as beginning some friendships which have lasted very well over the years. I think it strengthened my commitment to the value of international statistical co-operation.

Actually, I think I have enjoyed all the jobs that I have done. Really. I have been lucky. Whenever there was a possibility of a new job, I have always thought to myself that the job I am doing right now is actually the job that I always wanted to do. When I was the Head

\footnotetext{
${ }^{2}$ Len Cook took up the post of National Statistician and Director of the Office for National Statistics at the end of May 2000. He was the second head of the ONS, but the first to have the title of National Statistician. He led the creation and publication of the National Statistics Code of Practice.
}

of National Accounts, I thought that was a tremendous job and why would I want to do something else? But then I would move on, sometimes sideways, to another job, and I would think, actually, this new job is pretty good.

Interviewer: It sounds to me like you are the type of person that thrives on challenges?

Yes, I believe I do, and on something new and the thought that you might learn something. You kind of have to do some 'stretching'. You might know a bit about the subject, but there is always an awful lot more that you need to know. When you move, you also get an interesting group of new people to work with. It is a challenge and an inspiration.

That is what happened to me as I went from one job to the next. I always felt that I did not know all of it, and how interesting it would be to learn more.

Interviewer: It is probably good for us not to get too comfortable in any one position. It is good for us to be kicked out of our comfort zones every so often.

Yes, I think that is really important. You can get a bit stale. Talking to colleagues and getting them to understand that and getting that idea across is actually an important role for a senior manager. Trying to get people to see that being comfortable in an area is not always a good thing. This does not mean, we do not value experience. We value expertise. Especially, in some of the more technical jobs. But you do need to keep fresh. Experienced employees can give an awful lot to a new area.

Interviewer: What have been some of the challenges confronting you in your career?

One of the areas where I have tried to make improvements is in modernizing statistical architectures for statistical systems. It is difficult, and it was a challenge. I don't think we completely succeeded at ONS. I talked to people at ONS just the other day, and I am pleased to know that it is something they still have ambitions for, something they are still working on.

Interviewer: Tell us what you mean when you use the term 'modernize'. Also, you have written about the role of statistical leadership in the redesign of statistical systems. Please elaborate.

Traditionally, at the ONS and in other official statistical agencies, you will have statistical systems which would have been built for a particular purpose, e.g., for the labor force survey, for the census, for the retail prices index, for whatever the area of statistics they are talking about. Somebody would have sat down and said, "Okay. We need a statistical system, a computer system, a methodology that will do this. Here is the 
method, the practice and here is the tool." That is how it works. You look at the existing tools and you build something. When you look across the statistical offices, you will find that you have 50 or 60 systems, all of them separate, some of them linked together, some of them not.

Then as statistical thinking develops and the statistical methods improve, you have to try to introduce new thinking and new methods into a whole array of different tools and methods that are already in place. That is very difficult to do. They are out of date, and there is a high risk associated with them. You have to say, we cannot afford these systems, they are very expensive to maintain.

The thinking in many statistical offices now in the last ten years or so, is to try to modernize existing systems in a systematic way using a statistical architecture that works for the entire agency or at least for most of it. You are looking for common approaches: common software, common methods, common tools, common standards, metadata, and so on.

When you think about it, it is conceptually fairly simple. It is fairly easy to envision what it is going to look like, one big database, if you like, common ways of data input, common ways of data editing, of coding and encrypting, common ways of processing, across time series or cross sections, and common ways of putting the results up on the web.

There are huge advantages in terms of staff flexibilities, because once staff know how to do these things, they can easily move from one area to another. There is a lot more learning across the organization, people are far less compartmentalized.

The potential problem is the way all this is introduced. You want everybody to share the vision of how this should be done, because you have to do it bit by bit. You have to actually take a survey or a particular statistic and you have to modernize it to fit this new architecture.

There is the danger that you end up with highly detailed specifications as to how this should be done. You might get embroiled in bureaucracy and a lot of written requirements. You could spend an awful amount of time and money on just that aspect. There is also the danger that people will let go and will start going their own way and not in accordance with the plan.

In a way you want a series of projects set up where everybody really understands what you are trying to do, what you are going to do and why you are going to do it, and what the constraints are around what you are doing. The point being that you want to design a system, this huge architecture, in a way that is optimal for the office as a whole. You have to chose your methods, your software or whatever it might be in such a way that you can sustain it and maintain it over a long period. And you know that you can invest in it because the system is optimal for the office and every component within it.

In the process, you have to make compromises, you have to make choices. For example, the labor force people may come to you and say, that actually this is not the best system for them. "We would have preferred it some other way." If you are not careful, they can start tweaking it, reinventing the old system that they had. If they do not understand why it is done a certain way, it could become a real source of tension in an office. It is a challenge for the leadership. You have to promulgate the office-wide benefits and make them known. Make it a strategy that everybody understands. They can then get on with the redesign in their work area without it being too bureaucratic and too laborious.

If everybody gets it, and if everybody understands what you are trying to do, you can then delegate, leave it to them and entrust them to use the common tools in the best possible ways and come up with a system for their area without having to write down every possible thing that you need.

I have come to the conclusion that one of the hardest challenges that we face is developing that sort of system or architectural approach to the national statistical systems.

And everybody has struggled. Everybody has found it really difficult to do. We did not fully succeed at ONS while I worked there. We did do good stuff and we probably were quite good about setting up the vision, but we need to follow through.

Interviewer: You are hopeful that the implementation of your vision will happen?

I believe it will. It will be implemented in a rolling way. The vision changes after two or three years, as new things come along and you have to adapt. It is like painting the Forth Rail Bridge ${ }^{3}$ in Scotland [a colloquial expression for a never-ending task.] The story goes that by the time the painters get to the end of the job, they have to start again. It takes four years to paint this bridge. It is a bit like that. You just have to keep going, keep at it.

\footnotetext{
${ }^{3}$ The Forth Rail crosses the Firth of Forth a few miles west of Edinburgh. It was opened in 1890 and is $2,500 \mathrm{~m}$ long.
} 
Interviewer: Like painting the Forth Bridge - what a great analogy.

Another challenge I will mention is something I came to fairly late in my career. As Director General, I worked with a non-executive board. A few years ago there was a change in the governance of the UK statistical system and the UK Statistical Authority was created by Parliament. ${ }^{4}$

We used to have a fairly simple system. We had the Statistics Office reporting to a minister who himself reported to Parliament. There was the sense that this was not as independent as one would like a statistical office to be. There was no evidence of inappropriate pressure by the minister or the ministry on the statistical system. But, obviously, it was very difficult to demonstrate that there wasn't. So Parliament set up new arrangements.

The Statistical Authority took the place of the minister. This non-Executive Board is made up of dedicated people who take responsibility for the statistical system. They report directly to a parliamentary committee. ${ }^{5}$

The concept was fairly new and not something that I had been accustomed to in my career. As the Director General I found it quite challenging because the nonexecutives on the committee are not necessarily experts in statistics. Some of them certainly had a background in statistics, but most of them did not. They were more experts in public policy or they had other non-executive directorship experiences.

The members took and still do take their responsibility extremely seriously, because they are accountable to Parliament. Now the statistical systems are highly complex, and difficult to manage, and I must admit, I found that the relationship with the non-executives was not always easy. It needed a lot of skill to explain some of the statistical issues within the office. It was difficult, quite difficult, for example, to convey why change cannot always be implemented as quickly as we would like.

Also, as the Director General, you have a twoway relationship. You are the link between the nonexecutive board and your staff. You are trying to explain the views of the board to the staff and at the

\footnotetext{
${ }^{4}$ The UK Statistics Authority is an independent body operating as a non-ministerial department, directly accountable to Parliament. It was established on 1 April 2008 by the Statistics and Registration Service Act 2007.

${ }^{5}$ Membership of the Authority's Board comprises the Chair of the Authority, five other non-executive members, and three executive members.
}

same time explaining the statistical issues to the NonExecutive board.

I always struggled with that relationship. Looking back I think it would have been better had I been exposed to this governance system earlier in my career.

Interviewer: You have now joined the ranks of the retired. But you certainly did not retire from professional engagements. Tell us about your involvement. You are still very active in ISI and IAOS.

That is right. I was heavily involved with ISI when I was Director General. I was the president of the IAOS when I retired and I carried on with that for another year.

I have been and I still am chair of the ISI Advisory Board of Ethics and then recently, at the World Statistical Conference (WSC) in Rio (in July 2015), I was elected as a vice-president of ISI which continues for another four years.

It is a very active role. More active than I had imagined. We have executive committee meetings four times a year, but we also have fortnightly telephone conferences. There are four vice-presidents in ISI, and we get together with the President and the Presidentelect. We form the executive committee.

We are pretty hands-on. We work with the administrative office of ISI in The Hague, Netherlands. They perform the managing role. I have been helping them think through the ISI strategy. That is one area. I am also working with one of the other vice-presidents, Irena Krizman, on a workshop we are going to hold in Cameroon, in one of the francophone countries in West Africa. There is quite a lot to do there.

I am also involved with the Royal Statistical Society and it is helpful to compare the way the two organisations work - the ISI has a much smaller staff and is more dependent on the Executive Committee. Also, they have a different focus, with the ISI necessarily more involved in ethical issues and capacity building.

When I retired I decided to keep my involvement with statistics by working with the statistical professional associations rather than taking on consultancy work. There is a lot of statistical work, internationally, out there, for people who want to do that kind of work, particularly for official statisticians. I was not keen to do that. It seems an obvious thing to do, to maintain an interest in the professional statistical societies, to stay active through that kind of work. It keeps me in touch with people that I have known and worked with for many years around the world.

It also means that I can still travel quite a bit. I had the opportunity to go to Rio for the WSC, to Da Nang, 
Vietnam last year, and Hong Kong the year before that. Really exciting places to go to.

The nice thing now about being retired is that previously, when I would go to conferences, I would just go there and come back. Now my wife can go with me and we can have a week's holiday or something like that afterwards. My wife and I like to combine the statistical meetings I attend with wider travel.

Interviewer: Will you have a chance to go to Abu Dhabi in 2016?

Yes, I will. I have travelled to Abu Dhabi before. I know statisticians in the Statistics Centre of Abu Dhabi. It will be nice to meet them again. I am looking forward to that.

Interviewer: It may not be common knowledge to our readers, but you actually stepped in as the Editorin Chief of the Journal for a short period. How did that come about?

The circumstances were rather unfortunate and very sad. Frank Nolan was the Editor-in-Chief. He died suddenly (October 16, 2012). He collapsed in the street while out running - running was one of his favorite past-times. He was only 59 years old. Frank was Deputy Director for Population Methodology and Statistical Infrastructure at the ONS, a close colleague and a friend.

I had just retired. I was the president of IAOS and I did not see any other options than to pick up the reins and do that. The first priority of course was to find a replacement, a new editor. As you know, these things do take a while.

As it turned out, I was the interim editor for four or five months. It was something that I had never done before. Official statisticians do not get very deep into academic publishing, editing journals or anything like that. The task was completely new to me. I enjoyed it, but I was also quite glad to pass the baton on to Fritz Scheuren.

The experience did make me think more about the Journal. I had rather taken it for granted. You are faced with decisions such as "Do we really want to publish this or that manuscript?" I never wanted the Journal to be too technical. It always seemed to me that it is aimed at official statisticians, and the Journal needs to publish articles that they will find of use and of value. Articles that will excite their curiosity and interest. We have to keep it on that level, yet also relevant. We need articles that tackle the big issues in official statistics.

There is also the big problem of how to get official statisticians to write for publication in statistical journals. They do not have much time for that and writing and publishing is not valued that much by their peers and their bosses. It is an effort for them. It has to be worth their time. The statistical journal of IAOS gives them the outlet!

Interviewer: In addition to being an editor emeritus you are IAOS past president (2011-2013). In your strategic plan for the organization you stated:

"It is very difficult to get drive, energy and resources around a voluntary organization, whose members are scattered around the globe, mostly doing a full time job, rarely meeting and supported by a very small office. So my strategy for the IAOS was a simple one, namely to do more effectively what it tried to do, and use the vehicles at its disposal - the journal, the conference, etc."

Tell us more about your vision. How do you get volunteers to give so much of their time. How do you get it to work.

You have to always recognize that people are volunteers. Yes, you can stretch them, and challenge them and encourage them to do more, but you always have to bear in mind that if you push them too hard, they have a tendency to walk away, because they have so much else do to.

You have to be aware that people like to do things their own way. If you have an organization with a paid staff, to some extent you can insist on it being done your way. But when you are working with a group of volunteers, you cannot do that. You have to give encouragement, give advice and support.

I think the IAOS is very much a network. One of the strengths of the organization is bringing people together. One of the benefits of the conference is to get together. When we say hello on the first day, when people are meeting up again, they ask, "When are we getting together again? Are you free on Wednesday night? How about a bite to eat?" It is that kind of network, of old friends coming together again. That is so valuable. That gives strength to the network. That keeps things going.

As president of the organization, you have to be aware that there are limits to what people will do. You have to look at people's strengths, know what people are good at when you put a team together. For example, I chaired the Nominating Committee for the current IAOS Executive Committee. The search that we did was based on finding people who will work well together, people who have something to contribute to a team. Everybody has strengths and weaknesses. But in this context we really have to talk about the strengths and forget about the weaknesses. You have to get people to play to their strengths. 
Interviewer: I believe you have just given us the true definition of teamwork.

Interviewer: I would be amiss if I did not bring up another part of your post-retirement life. You are also involved in local politics. You are a local councillor?

It has always been politics at the local level. Already as a young man, as a teenager, I was involved with the Young Liberals which had a rather radical core. It was a small party, a third party here in the UK. I stood for the local council as a Liberal Democrat [in the London Borough of Sutton; one of the 32 boroughs that make up London] and was elected when I was about 30 years old. I was the deputy leader of the council (1988-91). I helped run the council. I was the chair of the Education Committee (1986-91). Overall, I served from 198394.

It gave me the political outlet that you do not have as a civil servant. It also developed my leadership skills which then helped me in my civil service career. However, there came a time when I could no longer afford to be involved. As my work and my career was taking off and became more important, the time pressures became difficult to manage.

Also, I was feeling that it was no longer appropriate to be involved. As a civil servant, you are allowed to serve. It is not prohibited. But, I felt it was not compatible with a more senior civil service post. So, for the latter part of my career, I got out of politics completely.

From 1994 to 2012, I had no involvement in local politics, but it was no more than six months into my retirement that somebody said, "Steve, why don't you get involved again?" So I stood once more, and I was elected again in 2014.

My political engagement takes up nearly two thirds of my time. I am currently lead member for the Arts, Heritage and Libraries. It is not too demanding, but there are pressing budget issues. There is always the scenario of cost cutting and lack of funding. This is always a threat for services and functions receiving government funding.

It is a shared problem for local councils in all parts of the UK and perhaps in other parts of the world. There is the tendency to think that the arts, theatre and music are nice things to have around, but not essentials. So on a personal note, I try to support them the best I can.

As I said, this commitment is a huge part of what I do, but I also have my professional statistical activities and involvements. In whatever time is left, I like to go to concerts and the theatre, do a bit of gardening, and since retirement, I have tried to learn golf. I am also involved in my local music festival.

I am probably just as busy as when I was working. It is a privilege to be retired and to be able to choose what you would like to do. The pressure is a lot less because it is up to you how far you want to get involved.

Interviewer: Are you an active musician or 'a consumer' of music. Have you taken up a musical instrument as well?

I play the piano, but not for anyone to listen to. I just enjoy music. We go to concerts and to the Opera. It is one of the advantages to living here in Sutton. We are able to go into the city, to London, very easily. As you know, London is a tremendous centre for the Arts. We can go into the city and come back home easily without it being too late at night. But we are part of the audience, not part of the orchestra!

It is actually rather strange to be talking about all this and be reflecting back on all these years. It was difficult to balance family life with a career. It was difficult to balance politics with work. What life is all about is balancing, making decisions about what is important, how you want to spend your time. That challenge is always there. Now, in retirement, it is the amount of involvement as a volunteer. You have to know when to say no, know what you want, being clear in your own mind about your priorities. Striking the balance. Do you get better at figuring it out as you grow older? Perhaps.

Interviewers: I hope you continue to enjoy an active, productive retirement. Thank you for all your service to the IAOS and to the SJIAOS and thank you for letting us get to know you a little bit better. The more interviews I do, the more I appreciate how much official statisticians all over the world have in common, not only in our professional, but also in our private lives.

You are welcome. I agree. There is a good amount of commonality. We all want to make a difference. We want to make an impact, no matter what we work on, no matter in what country we work. That is what drives us.

The telephone conversation between Stephen Penneck and Kirsten West took place on Saturday, December 5, 2015.

The views and opinions expressed in the interview are those of the interviewee and do not necessarily reflect the policy or position of the Statistical Journal of the International Association for Official Statistics nor IOS Press. 